\title{
Effect of Cu Addition on the Phase Equilibria in Nd-Fe-B Sintered Magnets
}

\author{
Shota Nishio ${ }^{1, * 1}$, Satoshi Sugimoto ${ }^{1,2}$, Ryota Goto $^{2}$, \\ Masashi Matsuura ${ }^{1, * 2}$ and Nobuki Tezuka ${ }^{1}$ \\ ${ }^{1}$ Department of Materials Science, Graduate School of Engineering, Tohoku University, Sendai 980-8579, Japan \\ ${ }^{2}$ New Industry Creation Hatchery Center (NICHe), Tohoku University, Sendai 980-8579, Japan
}

Nd-Fe-B sintered magnets show high energy products and have started to be used for motors of hybrid electric vehicles (HEVs). For the use of the magnets, the understanding of the coercivity mechanism is required for obtaining high coercivity. The $\mathrm{Nd}-$ rich phase in $\mathrm{Nd}-\mathrm{Fe}-\mathrm{B}$ sintered magnets plays an important role in cleaning the surface of $\mathrm{Nd}_{2} \mathrm{Fe}_{14} \mathrm{~B}$ grains for decreasing the number of nucleation sites of reverse domains, which leads to high coercivity. In this study, the phase equilibria including oxygen in Nd-Fe-B sintered magnets are discussed in view of the wettability between $\mathrm{Nd}$-rich phase and $\mathrm{Nd}_{2} \mathrm{Fe}_{14} \mathrm{~B}$ phase. It is considered that $\mathrm{Cu}$ addition decreases the free energy of $\mathrm{Nd}$-rich liquid phase, which leads to the shift of liquidus line of Nd-O system to lower temperature and the increase in solubility limit of oxygen. Due to improvement of wettability and increase in solubility limit, $\mathrm{Cu}$-added Nd-rich liquid spread easily and form homogeneous liquid phase during the sintering process. These phenomena enhance cleaning effect of Nd-rich phase and contribute to the increase in coercivity of Nd-Fe-B sintered magnets. [doi:10.2320/matertrans.MBW200824]

(Received October 20, 2008; Accepted January 20, 2009; Published March 4, 2009)

Keywords: neodymium-iron-boron magnet, neodymium-rich phase, wettability, sessile drop method, copper, triple junction

\section{Introduction}

After invention of $\mathrm{Nd}_{2} \mathrm{Fe}_{14} \mathrm{~B}$ magnets, ${ }^{1)}$ they are well known as the magnets with highest energy products among the other permanent magnets. Due to their high performance, Nd-Fe-B sintered magnets are used for several applications. Conventionally, the main application is voice coil motors in hard disk drives. Recently, the usage for driving motors in hybrid electric vehicles (HEVs) increases. Using for the driving motors, the magnets are required to have a high thermal stability because of the high temperature circumstances in driving motors. The Curie temperature of $\mathrm{Nd}-\mathrm{Fe}-\mathrm{B}$ sintered magnets is only $312^{\circ} \mathrm{C}$ and their coercivity decreases at high temperature. To obtain thermal stability and high coercivity, some amount of Dy is added to the Nd-Fe-B magnets. Because Dy has high magnetic anisotropy, addition of this element keeps high coercivity at high temperature. However, the magnetic moment of Dy is aligned antiparallel and decreases remanence. Moreover, natural abundance of Dy is low and its costs increases very rapidly.

Many researchers have contributed to the increase in saturation magnetic polarization up to about $97 \%$ of ideal values. However, the achievement of coercivity is only $12 \%$ of the ideal value. If the ideal coercivity is obtained, the thermal stability is considered to be enhanced without Dy addition. One of methods to increase coercivity is the improvement of the $\mathrm{Nd}_{2} \mathrm{Fe}_{14} \mathrm{~B}$ grain surfaces, as the coercivity mechanism of $\mathrm{Nd}-\mathrm{Fe}-\mathrm{B}$ sintered magnets is considered as the nucleation of reverse domains. If there are some defects on the surface of the $\mathrm{Nd}_{2} \mathrm{Fe}_{14} \mathrm{~B}$ grains, the reverse domains appear at low reverse magnetic field. Once a reverse domain appears in the grain, domain wall moves and magnetic reversal occurs very easily. Therefore, it is required

\footnotetext{
${ }^{* 1}$ Graduate Student, Tohoku University. Present address: Panasonic Corporation

${ }^{* 2}$ Graduate Student, Tohoku University
}

to decrease defects at the surface of $\mathrm{Nd}_{2} \mathrm{Fe}_{14} \mathrm{~B}$ grains for increasing coercivity. It is well known that Nd-rich phase plays an important role in cleaning the surface of $\mathrm{Nd}_{2} \mathrm{Fe}_{14} \mathrm{~B}$ grains and in decreasing the defects. ${ }^{2-7)}$

Although sufficient reaction is required between $\mathrm{Nd}_{2} \mathrm{Fe}_{14} \mathrm{~B}$ grains and very thin $\mathrm{Nd}$-rich grain boundary region, which is about $2 \mathrm{~nm},{ }^{6)}$ to achieve effective cleaning, there are little information about interfacial reaction between $\mathrm{Nd}_{2} \mathrm{Fe}_{14} \mathrm{~B}$ and Nd-rich phases. There are very few reports related to the wettability besides the report by Knoch et al. ${ }^{8,9)}$ in which the wettability was measured by the sessile drop method and both $\mathrm{Al}$ and Ga addition improve the wettability. In our previous work, ${ }^{10,11)}$ we investigated the wettability between $\mathrm{Nd}_{2} \mathrm{Fe}_{14} \mathrm{~B}$ and $\mathrm{Nd}$-rich phases through the sessile drop methods. $\mathrm{Cu}$ addition improves wettability and decreases the activation energy for wetting. And it is shown that the activation energy for wetting is related to the binding energy between Neodymium and Oxygen as Landry et $a{ }^{12)}$ have mentioned for $\mathrm{Al}$ alloys on the graphite substrate. In this report, the relationship between Nd-rich phase and oxygen, and the effect of $\mathrm{Cu}$ addition are discussed based on our previous report. ${ }^{10,11)}$ Finally, the phase transition during manufacturing process of sintered $\mathrm{Nd}_{2} \mathrm{Fe}_{14} \mathrm{~B}$ magnets, especially at triple junctions, is also discussed.

\section{Experimental}

The wettability was measured by the sessile drop method and a contact angle $(\theta)$ was adopted as a parameter of the wettability. The details were described in references. ${ }^{10,11)}$ Stoichiometric $\mathrm{Nd}_{2} \mathrm{Fe}_{14} \mathrm{~B}$ ingots and two kinds of $\mathrm{Nd}$-rich ingots were prepared. The compositions of Nd-rich ingots were $\mathrm{Nd}_{72.0} \mathrm{Fe}_{26.1} \mathrm{~B}_{1.9}$ (ternary) and $\mathrm{Nd}_{72.0} \mathrm{Fe}_{22.4} \mathrm{Cu}_{3.7} \mathrm{~B}_{1.9}$ ( $\mathrm{Cu}$-added), which were based on the eutectic composition of $\mathrm{Nd}-\mathrm{Fe}-\mathrm{B}$ system. ${ }^{13)}$ The amount of $\mathrm{Cu}$ addition was based on the report of Sakamoto et al. ${ }^{14)}$ 


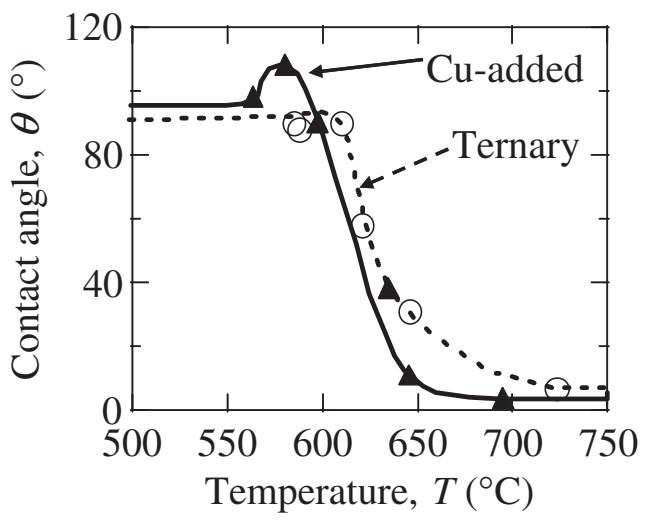

Fig. 1 The change of contact angles in equilibrium state for ternary (open circles and dashed line) and $\mathrm{Cu}$-added (closed triangles and solid line) ingots with increasing temperature.

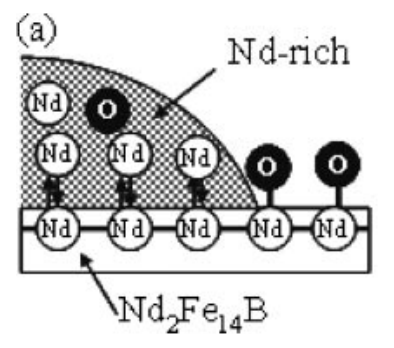

(b)

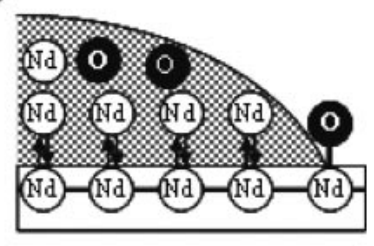

Fig. 2 Schematic images of Nd-rich liquid phase spreading on the $\mathrm{Nd}_{2} \mathrm{Fe}_{14} \mathrm{~B}$ phase. (a) and (b) show the state before and after the phenomenon in which Nd-rich liquid phase cuts the Nd-O bond at the surface of $\mathrm{Nd}_{2} \mathrm{Fe}_{14} \mathrm{~B}$ phase and dissolutes oxygen, respectively.

\section{Results and Discussion}

Annealing temperature dependence of the contact angle is shown in Fig. $1{ }^{10)} \mathrm{Cu}$-added Nd-rich ingots start to deform at lower temperature and show lower contact angles than ternary ones. It shows that the $\mathrm{Cu}$ addition improves the wettability between $\mathrm{Nd}_{2} \mathrm{Fe}_{14} \mathrm{~B}$ and $\mathrm{Nd}$-rich phases. The result that $\mathrm{Cu}$-added $\mathrm{Nd}$-rich ingots start to deform at lower temperature is clearly understood by the fact that $\mathrm{Cu}$ addition shifts the liquidus line of $\mathrm{Nd}-\mathrm{Cu}$ alloys to lower temperature. In our previous report, ${ }^{11)}$ the activation energy $(Q)$ for wetting is also evaluated from Arrhenius plot of the completion time $\left(t_{\text {comp }}\right)$. The $t_{\text {comp }}$ is defined as the time when the contact angle saturates at each holding temperature. From similar researches for wetting behaviors, e.g. the wetting behavior of $\mathrm{Al}$ alloy on a graphite substrate, ${ }^{12)}$ it is considered that wetting behavior in our previous work is related to the diffusion of adsorbed oxygen on the $\mathrm{Nd}_{2} \mathrm{Fe}_{14} \mathrm{~B}$ ingot into the Nd-rich molten alloy as shown in Fig. 2. A Nd$\mathrm{O}$ binary phase diagram is shown in Fig. $3 .{ }^{15)}$ One can see the liquid phase contains some amount of oxygen at the temperatures over $1010^{\circ} \mathrm{C}$. From the decline of liquidus line at the $\mathrm{Nd}$-rich side of $\mathrm{Cu}-\mathrm{Nd}$ binary system, liquidus line in the Nd-O binary system is expected to shift to lower temperature by $\mathrm{Cu}$ addition, as shown by the broken line in Fig. 3. It also yields the increase in solubility limit of oxygen into the liquid phase.

This phenomenon is also understood from our measurements of contact angles between $\mathrm{Nd}_{2} \mathrm{Fe}_{14} \mathrm{~B}$ and $\mathrm{Nd}$-rich

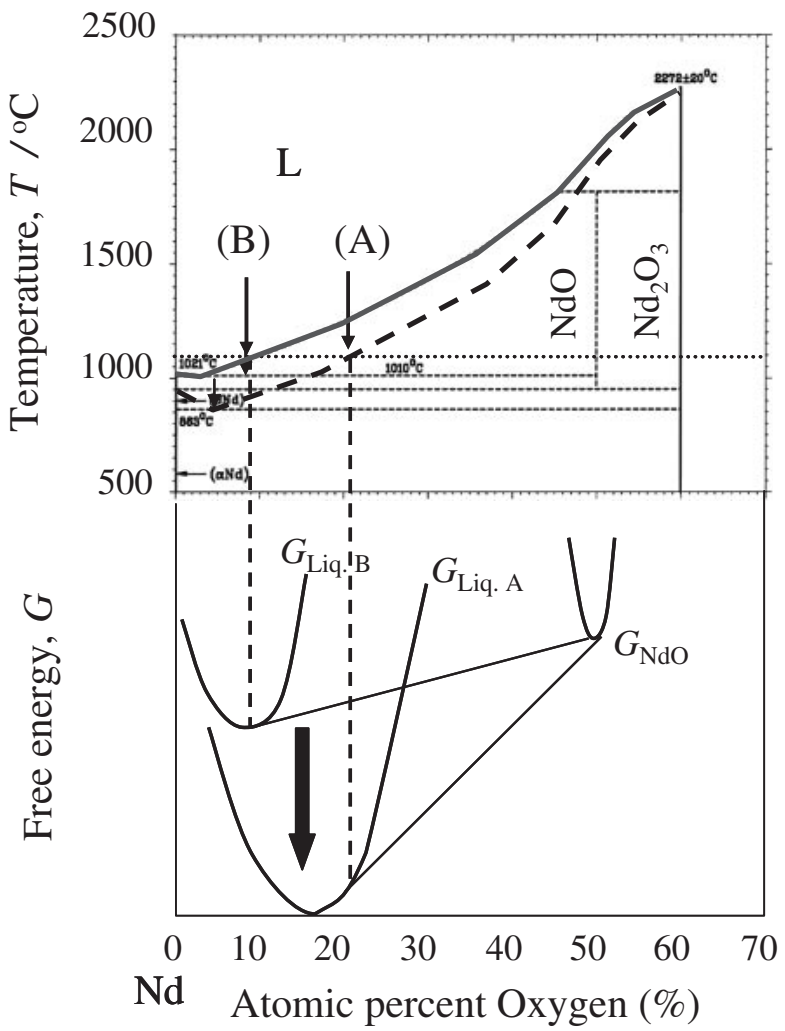

Fig. 3 The Nd-O binary phase diagram and corresponding schematic image of free energy-composition relationship. The expected liquidus line (dashed line) in the case of $\mathrm{Cu}$ added alloy is also shown in the $\mathrm{Nd}-\mathrm{O}$ binary phase diagram. The arrows (A) and (B) mean the solubility limit of oxygen in the liquid phase with or without $\mathrm{Cu}$, respectively.

phases. In Fig. 1, there is a peak of contact angle for the $\mathrm{Cu}-$ added alloy but not for the ternary one. It means that contact angle keeps the initial state for the ternary Nd-rich ingot but it increases for the $\mathrm{Cu}$-added one, and that the $\mathrm{Cu}$-added alloy changes the shape before the drastic change of contact angle. The photographs and schematic illustrations at the temperature when the shapes changes of Nd-rich ingots started are shown in Fig. 4. It is considered that Nd-rich ingots are covered with oxidized layers during heating process. However, the $\mathrm{Cu}$-added $\mathrm{Nd}$-rich ingot can dissolve larger amount of oxygen into liquid phase than the ternary $\mathrm{Nd}$-rich one. Therefore, thin oxidized layer is formed at the surface of $\mathrm{Cu}$ added Nd-rich ingot. Thin oxidized layer allows deformation of $\mathrm{Cu}$-added Nd-rich ingots due to surface tension of its liquid phase.

The change in the Nd-O phase diagram, particularly liquidus line, can also be discussed in terms of activation energy and free energy. Assuming that $\mathrm{Cu}$ addition shifts the liquidus line in the $\mathrm{Nd}-\mathrm{O}$ binary system to lower temperature and increases oxygen content in the liquid phase, the common tangent law in the free energy-composition relation of the Nd-O binary system requires that the free energy of liquid phase for the $\mathrm{Cu}$-added alloy should be lower than that for the ternary alloy, which is shown in the bottom panel of Fig. 3. The schematic illustration of the relationship between free energy and activation energy $(Q)$ is also shown in Fig. 5. Usually the activation energy is defined as the height of the potential barrier separating two minima of potential free 
(a) Ternary

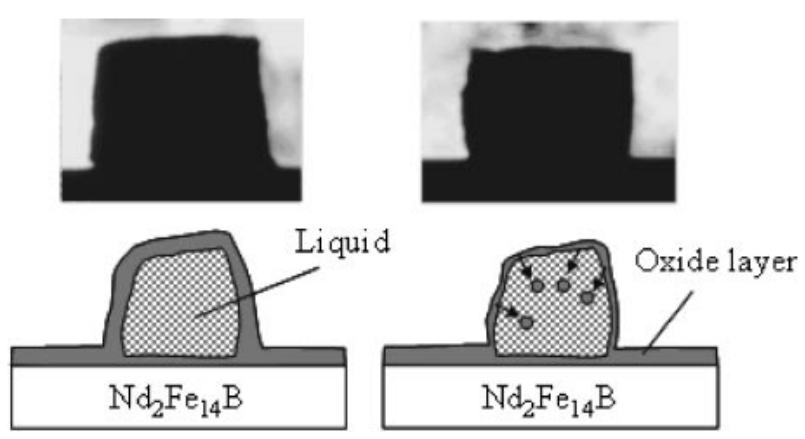

Fig. 4 The photographs and schematic illustrations of the Nd-rich ingots with or without $\mathrm{Cu}$ at the temperature when the shapes changes started.

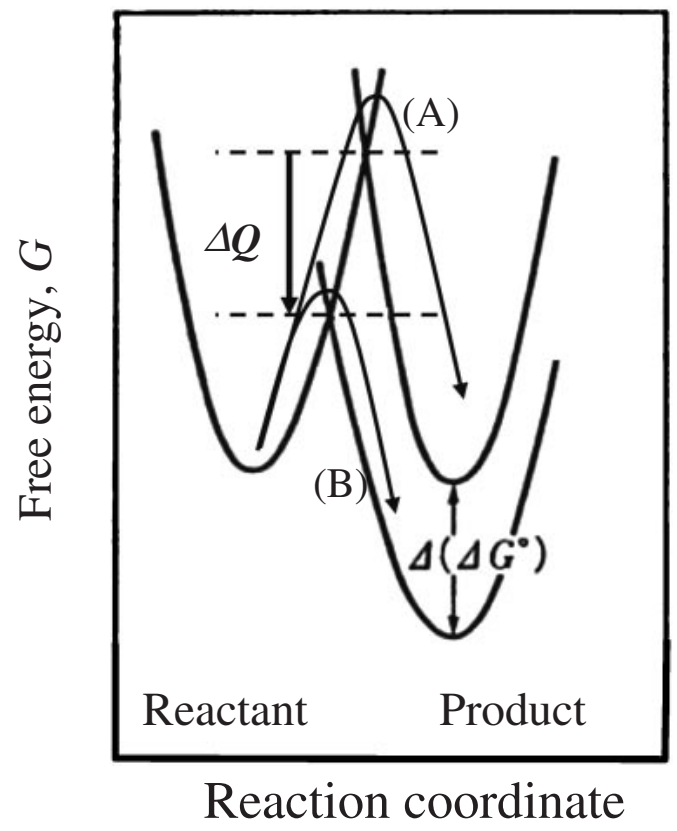

Fig. 5 The schematic image of relationship between free energy and activation energy.

energy of the reactants and of the products of reaction. Therefore, the activation energy is illustrated as the barrier height of the reaction indicated by the arrow (A) in Fig. 5. However, when the free energy of the product decreases, the reaction changes to the line arrowed (B) and the activation energy drops by $\Delta Q$. Our previous research about wettability ${ }^{11)}$ shows that the activation energy for the $\mathrm{Cu}$-added $\mathrm{Nd}$ rich ingot is lower than that of the ternary Nd-rich ingot. The activation energies are evaluated to be $196.8 \mathrm{~kJ} / \mathrm{mol}$ and $162.6 \mathrm{~kJ} / \mathrm{mol}$ for the ternary and the $\mathrm{Cu}$-added $\mathrm{Nd}$-rich ingots, respectively. ${ }^{11)}$ This result supports the assumption that the free energy of liquid phase decreases by $\mathrm{Cu}$ addition. Therefore, it is reasonable to explain the effect of $\mathrm{Cu}$ addition that $\mathrm{Cu}$ addition shifts the liquidus line of the $\mathrm{Nd}-\mathrm{O}$ system to lower temperature and increases the solubility limit of oxygen into Nd-rich liquid phase.

From the results and discussion described above, the microstructural change during the sintering and heat treatment processes of Nd-Fe-B sintered magnets is discussed. The sintering process is deeply related to the wettability and
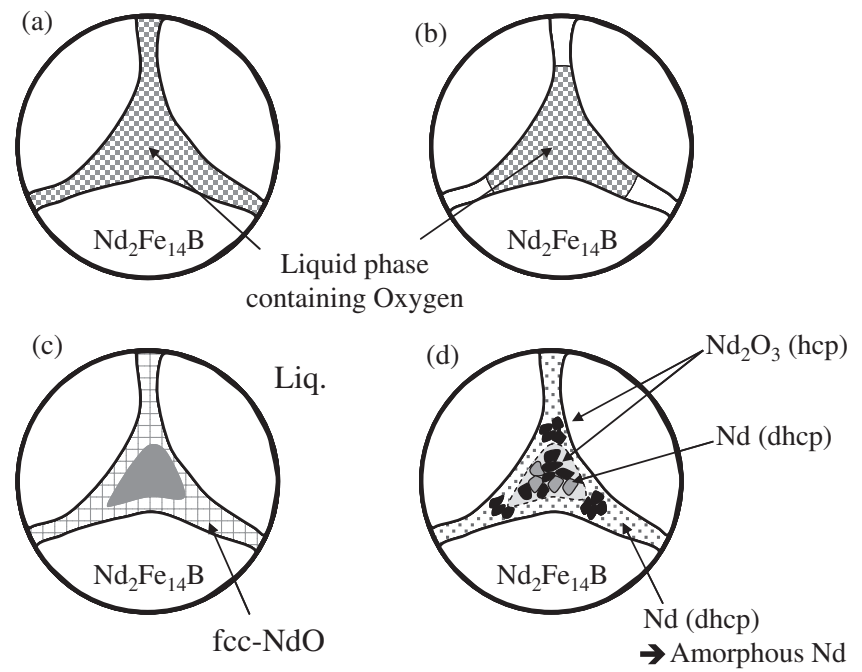

Fig. 6 Schematic images of the microstructural change during sintering ((a) and (b)), high temperature annealing (c) and final annealing (d) in $\mathrm{Cu}-$ added ((a), (c), and (d)) and ternary (b) Nd-Fe-B sintered magnets.

solubility limit of oxygen of Nd-rich phase. In the $\mathrm{Cu}$ added $\mathrm{Nd}-\mathrm{Fe}-\mathrm{B}$ alloys, Nd-rich phase contains some amount of $\mathrm{Cu}$ because the solubility limit of $\mathrm{Cu}$ in the $\mathrm{Nd}_{2} \mathrm{Fe}_{14} \mathrm{~B}$ phase is very small. ${ }^{16,17)}$ Therefore, $\mathrm{Cu}$ contained Nd-rich phase can melt at low temperature and the liquid phase can spread widely along $\mathrm{Nd}_{2} \mathrm{Fe}_{14} \mathrm{~B}$ grain boundaries as shown in Fig. 6(a). During the spreading, Nd-rich liquid phases dissolve the oxygen existing on the surface of $\mathrm{Nd}_{2} \mathrm{Fe}_{14} \mathrm{~B}$ main phases. In the case of ternary $\mathrm{Nd}-\mathrm{Fe}-\mathrm{B}$ alloys, the solubility limit of oxygen into $\mathrm{Nd}$ liquid phase is low and $\mathrm{Nd}$ rich liquid phase can contain small amount of oxygen. Moreover, the liquid phase cannot spread widely because the wettability of Nd-rich phase on $\mathrm{Nd}_{2} \mathrm{Fe}_{14} \mathrm{~B}$ grains is not good as shown in Fig. 6(b). On the contrary, in the case of $\mathrm{Cu}-$ added Nd-Fe-B alloys, the solubility limit of oxygen increases and the Nd-rich liquid phase can contain larger amount of oxygen than that in the alloys without $\mathrm{Cu}$. Therefore, it is concluded that the $\mathrm{Cu}$ addition is effective for the formation of homogeneous Nd-rich liquid phase, which spreads widely surrounding $\mathrm{Nd}_{2} \mathrm{Fe}_{14} \mathrm{~B}$ grains and contains relatively large amount of oxygen, during sintering.

Conventional $\mathrm{Nd}-\mathrm{Fe}-\mathrm{B}$ sintered magnets are heat-treated by two-step annealing after sintering. Namely, the sintered bodies are annealed at temperatures around $900^{\circ} \mathrm{C}$ (high temperature annealing) and then final-annealed at temperatures around $500-650^{\circ} \mathrm{C}$ (final annealing). The details and the roles of these annealing are not clear but these annealing processes are considered to be the processes for controlling the microstructure of precipitated phases. From the discussion described above and the Nd-O binary phase diagram, ${ }^{15}$ ) it is considered that fcc- $\mathrm{NdO}$ phase precipitates at along the $\mathrm{Nd}_{2} \mathrm{Fe}_{14} \mathrm{~B}$ grains from liquid phase during the high temperature annealing. It is natural to think that the fcc- $\mathrm{NdO}$ precipitates around the $\mathrm{Nd}_{2} \mathrm{Fe}_{14} \mathrm{~B}$ main phase and liquid phase remains at the center of triple junctions as shown in Fig. 6(c), judging from the differences of melting points between fcc-NdO and $\mathrm{Nd}$ (dhcp). In this stage, the effect of $\mathrm{Cu}$ addition is considered as follows; more homogeneous 
liquid phase formed during sintering process in the case of $\mathrm{Cu}$ added alloys is considered to change to more homogeneous fcc-NdO phase and the phase spreads wider region than those in the case of ternary alloys.

From the Nd-O binary phase diagram, ${ }^{15)}$ the final annealing at low temperature is considered to have two kinds of microstructure changes. The schematic image of microstructure is shown in Fig. 6(d). One is that the liquid phase is decomposed into dhcp- $\mathrm{Nd}$ and hcp- $\mathrm{Nd}_{2} \mathrm{O}_{3}$. If the liquid phase after the high temperature annealing exists at the center of triple junctions, as described above, it is considered that the precipitated dhcp- $\mathrm{Nd}$ and hcp- $\mathrm{Nd}_{2} \mathrm{O}_{3}$ from liquid phase do not contact with $\mathrm{Nd}_{2} \mathrm{Fe}_{14} \mathrm{~B}$ main phases. Fukagawa and Hirosawa ${ }^{18)}$ have reported that dchp-Nd does not contribute to the recover of coercivity even after annealing. Therefore, it can be said that the roles of high temperature annealing are to precipitate the fcc-NdO from the liquid phase along the $\mathrm{Nd}_{2} \mathrm{Fe}_{14} \mathrm{~B}$ grains and to move the residual liquid phase at the center of triple junctions. The other microstructure change during final annealing is the formation of amorphous phases at the interface with $\mathrm{Nd}_{2} \mathrm{Fe}_{14} \mathrm{~B}$ main phases. Our recent study, ${ }^{19)}$ in which a model interface between $\mathrm{Nd}_{2} \mathrm{Fe}_{14} \mathrm{~B}$ and Nd-rich phase was fabricated using a thin film technique, revealed that an amorphous phase with thickness less than $4 \mathrm{~nm}$ forms along the $\mathrm{Nd}_{2} \mathrm{Fe}_{14} \mathrm{~B}$ phases during final annealing and suggested that the phase plays an important role in decreasing nucleation sites of reverse domains and in generating coercivity. In addition, the phase is considered to form by the transformation from fcc-NdO to dchp-Nd and hcp- $\mathrm{Nd}_{2} \mathrm{O}_{3}$, and the release of the strain at the interface. Details are shown in our previous paper. ${ }^{19)}$ Therefore, the homogeneous formation of fcc-NdO phase is important for the formation of the amorphous phase and the generation of coercivity. It is concluded that the effect of $\mathrm{Cu}$ addition to $\mathrm{Nd}-\mathrm{Fe}-\mathrm{B}$ sintered magnets is the improvement of wettability of Nd-rich phase leading to the homogeneous formation of $\mathrm{Nd}$-rich liquid, fcc-NdO and amorphous phases in each heat treatment process, which results in high coercivity. However, the coercivity of $\mathrm{Nd}-\mathrm{Fe}-\mathrm{B}$ sintered magnets is still smaller than the ideal value. Li et al. ${ }^{20}$ ) have reported that the inhomogeneous Nd-rich distribution yields decrease in coercivity for Nd-Fe-B sintered magnets. Therefore, decrease in coercivity may be caused by the residual reversal domains or impurity e.g. oxygen at the main phase grains due to insufficient cleaning effect.

\section{Conclusion}

The effect of $\mathrm{Cu}$ addition was discussed from the relationship between Nd-rich phase and oxygen using the results of our previous works. The effect of $\mathrm{Cu}$ addition to $\mathrm{Nd}-\mathrm{Fe}-\mathrm{B}$ sintered magnets is considered as the increase in solubility limit of oxygen into Nd-rich liquid phase by lowering the liquidus line in $\mathrm{Nd}-\mathrm{O}$ binary phase diagram. This means $\mathrm{Nd}$-rich liquid phase with $\mathrm{Cu}$ can dissolve larger amount of oxygen than the Nd-rich liquid phase without $\mathrm{Cu}$.

The phase transition of Nd-Fe-B sintered magnets during sintering and annealing processes was also discussed. The following effects of $\mathrm{Cu}$ addition on these processes are considered.
(1) (Sintering) Improvement of wettability between $\mathrm{Nd}_{2}$ $\mathrm{Fe}_{14} \mathrm{~B}$ and Nd-rich phases and the wide spread of homogeneous liquid phase with relatively large amount of oxygen.

(2) (High temperature annealing) The formation of homogeneous fcc-NdO phase along $\mathrm{Nd}_{2} \mathrm{Fe}_{14} \mathrm{~B}$ grains and residual liquid phase at the center of triple junctions.

(3) (Final annealing) The formation of more homogeneous amorphous phase along $\mathrm{Nd}_{2} \mathrm{Fe}_{14} \mathrm{~B}$ phases by the transformation from homogeneous fcc-NdO phase and the release of strain at the interface with $\mathrm{Nd}_{2} \mathrm{Fe}_{14} \mathrm{~B}$ grain.

\section{Acknowledgement}

A part of this study was financially supported by a Rare Metal Substitute Materials Development Project (Development of technology for reducing dysprosium usage in a rareearth magnet) from the METI and NEDO in Japan, Pilot research for reducing dysprosium usage in a rare-earth magnet from the NEDO in Japan, and Grant-in-Aid for Scientific Research (Scientific Research of Priority Areas "Panoscopic Assembling and High Ordered Functions for Rare Earth Materials (No. 16080202)") from the MEXT in Japan. The authors also thank Santoku Corporation for providing $\mathrm{Nd}_{2} \mathrm{Fe}_{14} \mathrm{~B}$ and Nd-rich ingots.

\section{REFERENCES}

1) M. Sagawa, S. Fujimura, N. Togawa, H. Yamamoto and Y. Matsuura: J. Appl. Phys. 55 (1984) 2083-2087.

2) K. J. Strnat: Ferromagnetic Materials, vol. 4, K. H. J. Buschow (ed.), (North-Holland Publishing, Amsterdam, 1989) p. 131.

3) M. Sagawa, S. Fujimura, H. Yamamoto, Y. Matsuura and K. Hiraga: IEEE Trans. Magn. MAG-20 (1984) 1584-1589.

4) D. Eckert, D. Hinz, A. Handstein and J. Schneider: Phys. Status. Sol. A 101 (1987) 563-566.

5) Y. Tsubokawa, S. Hirosawa and R. Shimizu: Jpn. J. Appl. Phys. 29 (1990) 2737-2740.

6) F. Vial, F. Joly, E. Nevalainen, M. Sagawa, K. Hiraga and K. T. Park: J. Magn. Magn. Mater. 242-245 (2002) 1329-1334.

7) G. F. Zhou, S. Y. Fu, X. K. Sun and Y. C. Chuang: Phys. Stat. Sol. A 121 (1990) 257-264.

8) K. G. Knoch, E.-Th. Heing and J. Fidler: J. Magn. Magn. Mater. 83 (1990) 209-210.

9) K. G. Knoch, B. Grieb, E.-Th. Henig, H. Kronmüler and G. Petzow: IEEE Trans. Magn. 26 (1990) 1951-1953.

10) S. Nishio, R. Goto, M. Matsuura, N. Tezuka and S. Sugimoto: J. Japan Inst. Metals 72 (2008) 1010-1014.

11) R. Goto, S. Nishio, M. Matsuura, S. Sugimoto and N. Tezuka: IEEE Trans. Magn. 44 (2008) 4232-4234.

12) K. Landry, S. Kalogeropoulou and N. Eustathopoulos: Mater. Sci. Eng., A 254 (1998) 99-111.

13) D. S. Tsai, T. S. Chin, S. E. Hsu and M. P. Hung: IEEE Trans. Magn. MAG-23 (1987) 3607-3609.

14) A. Sakamoto, T. Hidaka, C. Ishizaka, N. Uchida and A. Fukuno: Trans. Mater. Res. Soc. Jpn. 29 (2004) 1719-1722.

15) Ed. ASM International: Binary Alloy Phase DIAGRAMS: Plus Updates (CD-ROM), (ASM International, Ohio, 2005).

16) J. Fidler: 6th Int. Symp. On Mag. Anisotropy and Coercivity in RE Transition Metal Alloys at Canberra (1992) p. 11.

17) K. Raviprasad, N. Ravishankar, K. Chattopadhyay and M. Umemoto: J. Appl. Phys. 83 (1998) 916-920.

18) T. Fukagawa and S. Hirosawa: J. Appl. Phys. 104 (2008) 013911.

19) M. Matsuura, S. Nishio, R. Goto, S. Sugimoto and N. Tezuka: J. Appl. Phys. in press.

20) W. F. Li, T. Ohkubo, K. Hono and M. Sagawa: J. Magn. Magn. Mater. (2008) doi: 10.1016/j.jmmm 2008.10.032. 